\title{
Study on the Mechanism of Protective Effect of Tannic Acid on the Myocardial Hypertrophy Induced By Pressure Overload
}

\author{
XIN GUO, LULU WANG, X. LI, MIN YU, Y. XU AND JIANMING LI* \\ Department of Cardiovascular Medicine, Affiliated Taikang Xianlin Drum Tower Hospital, Medical School of Nanjing University, \\ Nanjing, Jiangsu 210034, China
}

Gau et al.: Mechanism of Protective Effect of Tannic Acid on Myocardial Hypertrophy

\begin{abstract}
Cardiac hypertrophy was a compensatory response to normal cardiac pressure overload, which eventually leads to heart failure. Therefore, the research of new drugs for the treatment of cardiac hypertrophy was one of the hotspots. In this paper, we explore the protective effect of tannic acid on myocardial hypertrophy and its potential mechanism. The rat model of cardiac hypertrophy was established by abdominal aortic banding. According to the random control principle, the rats treated with sham operation were used as the control group. Abdominal aortic banding rats were treated with tannic acid (20 and $40 \mathrm{mg} / \mathrm{kg})$ or captopril and divided into low dose tannic acid group, high dose tannic acid group, and captopril group. The hemodynamic parameters of rats in each group were detected respectively, and then the related proteins and tissues were detected after the rats were killed. The results showed that the cardiac morphology and pathology of abdominal aortic banding rats treated with tannic acid were significantly improved, myocardial hypertrophy and apoptosis were decreased and the overexpression of Angiotensin II type 1 receptor and Angiotensin II type 2 receptor was decreased. In addition, the messenger Ribonucleic acid expression of extracellular signal regulated kinase $1 / 2$, transforming growth factor- $\beta$ and matrix metalloproteinase-9 decreased. At the same time, tannic acid treatment decreased the activity and content of malondialdehyde and endothelin-1, and increased the content of superoxide dismutase, catalase, glutathione peroxidase, nitric oxide, and endothelial nitric oxide synthase. In addition, tannic acid downregulated the expression of tumor necrosis factor- $\alpha$, interleukin-1 $\beta$, B-cell lymphoma-2 associated $X$ protein and cysteine-dependent aspartate specific proteases-3 and up-regulated the expression of $B$-cell lymphoma-2. Tannic acid treatment can improve abdominal aortic banding induced cardiac hypertrophy effectively. Its cardioprotective effect is partly attributed to the reduction of myocardial oxidative stress, inhibition of inflammation, inhibition of fibrosis, reduction of apoptosis, increase of nitric oxide level, decrease of endothelin-1 level, and down-regulation of Angiotensin II type 1 receptor.
\end{abstract}

Key words: Myocardial hypertrophy, tannic acid, myocardial oxidative stress, abdominal aortic banding

Cardiovascular disease (CVD) was the leading cause of disease death worldwide. Pathological studies have shown that the cardiac hypertrophy was a symptom of the heart stimulated by a variety of CVD, including myocardial hypertrophy, hypertension, cardiomyopathy, coronary heart disease, and cardiac vascular disease ${ }^{[1,2]}$. Cardiac hypertrophy was caused by the increase of cardiac contractile protein and accessory protein $^{[3]}$. In the initial stage, cardiac hypertrophy was a compensatory response to the normal cardiac function, but in the later stage, maladaptation leads to the progressive and pathological myocardial hypertrophy, which eventually leads to heart failure ${ }^{[4-7]}$. Therefore, there is an urgent need to find new drugs to treat cardiac hypertrophy and prevent or reverse its progress ${ }^{[7]}$. Epidemiological studies have shown that although the French people eat a high cholesterol diet, they have a lower mortality rate of CVD than other developed countries. The reason may be related to the strong consumption of French red wine, which supports the hypothesis that red wine has a protective effect on the heart. In addition, the red wine can inhibit and prevent various $\mathrm{CVDs}^{[8]}$. Previous studies have shown that the resveratrol, rich in the red wine, plays an important

*Address for correspondence

E-mail: zgrljm@sina.com

Special Issue 8, 2020 
role in heart protection ${ }^{[8,9]}$. However, resveratrol, also rich in the white wine does not seem to have the same cardioprotective effect as the red wines. When red wine was given to the healthy volunteers, resveratrol seemed to improve their lipoprotein cholesterol and lead to an increase in plasma antioxidant status ${ }^{[10]}$. Tannic acid (TA) also known as tannin, was a natural polyphenol compound widely found in the human diet (red wine and tea) ${ }^{[11]}$. TA content in red wine was much higher than that in the white wine ${ }^{[12]}$. Many studies have shown that TA has antioxidant ${ }^{[13,14]}$, antimutagenic ${ }^{[15]}$, antiinflammatory ${ }^{[16,17]}$, and anti-proliferative activity ${ }^{[18]}$. Recently, some studies have reported that TA inhibits the expression of angiotensin II type 1 receptor (AT1R) gene through mitogen-activated protein kinase (MAPK)-dependent pathway, which was related to the progression of cardiomyocyte fibrosis ${ }^{[19]}$. However, its protective mechanism against cardiac hypertrophy was not completely clear. In this paper, the potential mechanism of the myocardial protective effect of TA after abdominal aortic banding (AAB) was studied by analyzing the hypertrophy related molecules, markers of oxidative stress, inflammatory cytokines, fibrosis, and apoptosis factors.

\section{MATERIALS AND METHODS}

\section{Chemical reagents and materials:}

TA was purchased from Tianjin Kemiou Chemical Reagent Co., Ltd. Captopril (CAP) was purchased from Guangdong Weng Jiang Reagnt Co., Ltd. The test kit was obtained from Thermo Fisher Scientific Inc. Unless otherwise specified, other chemicals were purchased from Thermo Fisher Scientific Inc.

\section{Animals:}

Adult Wistar rats (200 g-240 g) were provided by the Experimental Animal Center of Sun Yat-sen University. All the animal experiments in our study were in line with the guidelines for animal experiments, which come from the Declaration of Helsinki of the Medical Ethics Committee of the Ministry of Health of China.

\section{Experimental methods:}

Adult Wistar rats underwent the operation after at least $3 \mathrm{~d}$ of adaptation. Before the operation, the animals were anesthetized with ethyl carbamate $(4 \mathrm{mg} / \mathrm{kg})$, and the model was made according to AAB method ${ }^{[20]}$. After closing the abdomen, the animals were injected with penicillin $\mathrm{G}$ (10 000 Units per rat) and allowed free access to food and water. In the control group, the sham operation was performed in the same way, but aortic coarctation was not performed.

$4 \mathrm{w}$ later, all the animals were divided into five groups $(\mathrm{n}=8)$ : sham operation (Sham) group, AAB group, low dose TA (LTA)-AAB group (20 mg/kg/d, LTA group), high dose TA (HTA)-AAB group (40 mg/kg/d, HTA group), and captopril-AAB group $(20 \mathrm{mg} / \mathrm{kg} / \mathrm{d}$, CAP group). From $4 \mathrm{w}$ after the operation, the drug was dissolved in water and injected into the peritoneum for 4 $\mathrm{w}$, and the animals in $\mathrm{AAB}$ and Sham groups were given the same volume of water. During the experiment, the body weight was measured every week, and the general characteristics of all rats were carefully observed.

At the end of the experiment, we recorded the final weight of each animal and evaluated the hemodynamics of the surviving animals. The blood samples were taken from the arteria carotis communis of rats for later analysis.

\section{Hemodynamic and morphological analysis:}

The rats were anesthetized with chloral hydrate $(3 \mathrm{mg} /$ $\mathrm{kg}$, intravenous injection), and the cardiac function was measured by the electrocardiogram limb leads (Electrocardiogram). The electrocardiogram was recorded with pin electrode and BL-420S biological data acquisition and analysis system. A tube filled with heparinized saline and connected to the pressure sensor (1.1 $\pm 9.5 \mathrm{~mm}$ diameter vein intubation) was inserted into the blood vessel and pushed into the left ventricle to record the left ventricular pressure. Left ventricular systolic pressure (LVSP), left ventricular end diastolic pressure (LVEDP), maximum contraction rate $(+\mathrm{dp} /$ dtmax) and diastolic rate (-dp/dtmax) were calculated from the left ventricular pressure pulse. The blood samples were collected from the animals. At the end of the animal experiment, the heart weight (HW) and body weight $(\mathrm{BW})$ of the rats were measured to calculate the heart weight index (HW/BW). The myocardial tissue was preserved in $4 \%$ paraformaldehyde solution for $24 \mathrm{~h}$ and embedded in paraffin to make heart sections, and the histopathology was observed by hematoxylineosin staining (H\&E staining). Myocardial fibrosis in cardiac sections was examined by Masson staining. A digital microscope with a multi-functional image analysis system was used to determine the percentage area of positive Mason's trichromatic and the representative microphotographs of heart sections. 
Detection of creatine kinase (CK), creatine kinase myocardial band (CK-MB), and lactate dehydrogenase (LDH):

All experimental rats were anesthetized with chloral hydrate $(3 \mathrm{mg} / \mathrm{kg})$, and the activities of creatine kinase $(\mathrm{CK})$ and creatine kinase myocardial band (CK-MB) in serum and the content of lactate dehydrogenase (LDH) in plasma were measured.

\section{Detection nitric oxide (NO) and endothelin-1:}

The blood was collected and centrifuged at $999 \mathrm{~g}$ for $10 \mathrm{~min}$. All samples were analyzed at $280^{\circ}$. Because of the instability of nitric oxide (NO), most NO was often converted to nitrite $\left(\mathrm{NO}_{2}\right)$ or nitrate $\left(\mathrm{NO}_{3}\right)$ for detection. According to the manufacturer's instructions, we used a $\mathrm{NO}$ detection kit for the detection of $\mathrm{NO}_{2}$ in plasma. The content of endothelin-1 was determined by a rat endothelin-1 enzyme-linked immunosorbent assay kit.

\section{Detection of oxidation markers:}

The heart tissues were rinsed with cold isotonic saline, and then freeze it with liquid nitrogen immediately. The heart tissues of the control group and the experimental group were homogenized (10 \% weight/volume), re-suspended with phosphate buffer $(50 \mathrm{mM}, \mathrm{pH} 7.4)$ and weighed after centrifugation. After centrifugation at $8000 \mathrm{rpm} / \mathrm{min}$ for $20 \mathrm{~min}$, the supernatant was used for biochemical analysis. The activities of catalase, glutathione peroxidase, and superoxide dismutase, and the content of malondialdehyde (MDA) in heart samples were determined by spectrophotometry.

\section{Western blot:}

Radioimmunoprecipitation assay (RIPA) lysis buffer was used for the homogenization of the infarcted myocardial tissue around the left ventricular region. The proteins in heart tissue lysates were separated by sodium dodecyl sulfate polyacrylamide gel electrophoresis (SDS-PAGE) and then transferred to polyvinylidene fluoride (PVDF) membrane. The membrane was incubated with AT1R, Angiotensin II type 2 receptor (AT2R), phospho-extracellular signal regulated kinase $1 / 2$ (p-ERK1/2), endothelial nitric oxide synthase (e-NOS), B-cell lymphoma-2 associated $\mathrm{X}$ protein (bax), B-cell lymphoma-2 (bcl-2) or cysteinedependent aspartate specific proteases-3 antibodies overnight at $4^{\circ}$. The horseradish peroxidase labeled secondary antibody (1:300) was incubated with the membrane for $2 \mathrm{~h}$. The enhanced chemiluminescence detection reagent was used to display the immune reaction zone in the gel imaging system.

\section{Immunohistochemical analysis:}

After paraffin removal, $4 \mathrm{~mm}$ thick left ventricular tissue sections were used for immunohistochemical analysis. Microwave antigen repair was performed in citrate buffer ( $\mathrm{pH} \mathrm{6.0)}$ ) for $10 \mathrm{~min}$, and then incubated with $3 \%$ Hydrogen peroxide $\left(\mathrm{H}_{2} \mathrm{O}_{2}\right)$ for $10 \mathrm{~min}$. After washing, the non-specific epitope was blocked by immunoglobulin and $5 \%$ serum at $37^{\circ}$ for $15 \mathrm{~min}$. The sections were incubated with the diluted rabbit polyclonal antibodies against interleukin-1 $\beta$ (IL-1 $\beta$ ) (1:200), tumor necrosis factor- $\alpha$ (TNF- $\alpha$ ) (1:200), transforming growth factor- $\beta$ (TGF- $\beta$ ) $(1: 100)$, matrix metalloproteinase-9 (MMP-9) (1:100), c-fos and c-jun (1:100) at $4^{\circ}$ for overnight. Then the tissue sections were stained with streptavidin/peroxidase complex at $37^{\circ}$ for $15 \mathrm{~min}$ before adding the substrate solution of 3, 3'-Diaminobenzidine (DAB). The sections were then re-stained in hematoxylin and photographed under a digital microscope. At the same time, the control staining was carried out, and the phosphate buffer was used instead of the primary antibody. We randomly selected 50 regions under $400 \pm 9$ magnification to determine the expression of IL- $1 \beta$, TNF- $\alpha$, TGF- $\beta$, MMP-9, c-fos and c-jun (positive area $=$ staining area/ total tissue area).

\section{Statistical analysis:}

The data were displayed as average \pm standard error of mean (SEM). One-way analysis of variance (ANOVA) was carried out with statistical package for the social sciences (SPSS) 20.0 software, and multiple comparisons were made. $\mathrm{p}<0.05$ indicates that the difference was statistically significant.

\section{RESULTS AND DISCUSSION}

The results showed that the heart rate caused by the coarctation of aorta was increased significantly than those in the sham group $(\mathrm{p}<0.01)$. On the contrary, compared with the sham group, AAB caused a significant decrease in LVSP and $+\mathrm{dp} / \mathrm{dtmax}(\mathrm{p}<0.01)$. Compared with the LTA group, the cardiac function parameters of the HTA group were closer to the normal value. TA with the concentration of $100 \mathrm{mg} / \mathrm{kg}$ has a better protective effect (Table 1).

Compared with the sham group, the body weight ratio of the AAB group (Table 2) was significantly increased, while in the TA or CAP treatment group, the body weight 
TABLE 1: EFFECTS OF TA ON HEMODYNAMICS

\begin{tabular}{lcccccc}
\hline Group & Cases & HR $(\mathrm{bpm})$ & LVEDP $(\mathrm{mmHg})$ & LVSP $(\mathrm{mmHg})$ & + dp/dtmax $(\mathrm{mmHg} / \mathrm{s})$ & $\mathrm{dp} / \mathrm{dtmax}(\mathrm{mmHg} / \mathrm{s})$ \\
\hline Sham group & 10 & $340 \pm 3$ & $4.35 \pm 0.18$ & $141 \pm 3.20$ & $4715 \pm 65$ & $4602 \pm 58$ \\
AAB & 10 & $396 \pm 5$ & $7.10 \pm 0.25^{\mathrm{a}}$ & $102 \pm 5.31^{\mathrm{a}}$ & $2358 \pm 53^{\mathrm{a}}$ & $2588 \pm 39^{\mathrm{a}}$ \\
LTA & 10 & $368 \pm 7$ & $6.22 \pm 0.11^{\mathrm{b}}$ & $127 \pm 2.50^{\mathrm{b}}$ & $4288 \pm 82^{\mathrm{b}}$ & $4397 \pm 63^{\mathrm{b}}$ \\
HTA & 10 & $356 \pm 9$ & $5.12 \pm 0.09^{\mathrm{b}}$ & $136 \pm 5.90^{\mathrm{b}}$ & $4478 \pm 32^{\mathrm{b}}$ & $4544 \pm 27^{\mathrm{b}}$ \\
CAP & 10 & $347 \pm 6$ & $4.57 \pm 0.06^{\mathrm{b}}$ & $135 \pm 6.10^{\mathrm{b}}$ & $4699 \pm 21^{\mathrm{b}}$ & $4607 \pm 15^{\mathrm{b}}$ \\
\hline
\end{tabular}

a: Compared with the sham group, $p<0.05$; b: Compared with the $A A B$ group, $p<0.05$

TABLE 2: THE INFLUENCE OF TA ON BW, HW, AND HW/BW

\begin{tabular}{lcccc}
\hline Group & Cases & HW $(\mathbf{g})$ & BW $(\mathbf{g})$ & HW/BW $(\mathrm{mg} / \mathrm{g})$ \\
\hline Sham group & 10 & $1014.3 \pm 35.0$ & $333 \pm 5$ & $3.05 \pm 0.06$ \\
AAB & 10 & $1315 \pm 19.5^{\mathrm{a}}$ & $349 \pm 4^{\mathrm{a}}$ & $3.79 \pm 0.11^{\mathrm{a}}$ \\
LTA & 10 & $1207 \pm 57.6$ & $341 \pm 5$ & $3.53 \pm 0.07$ \\
HTA & 10 & $1085 \pm 33.2^{\mathrm{b}}$ & $316 \pm 4^{\mathrm{b}}$ & $3.43 \pm 0.06^{\mathrm{b}}$ \\
CAP & 10 & $1074 \pm 28.8^{\mathrm{b}}$ & $319 \pm 5^{\mathrm{b}}$ & $3.36 \pm 0.08^{\mathrm{b}}$ \\
\hline
\end{tabular}

a: Compared with the sham group, $p<0.05$; b: Compared with the $A A B$ group, $p<0.05$

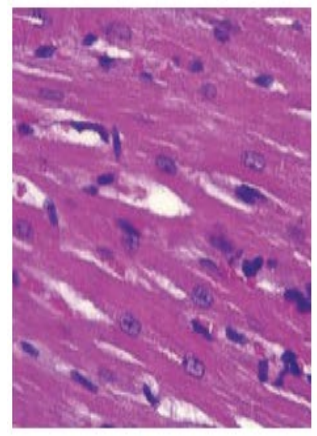

A

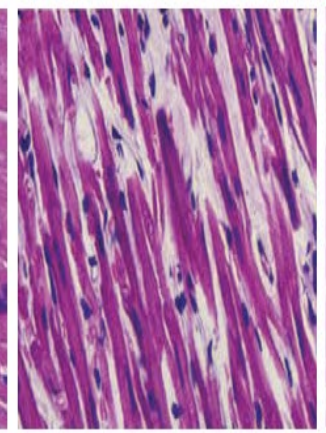

B

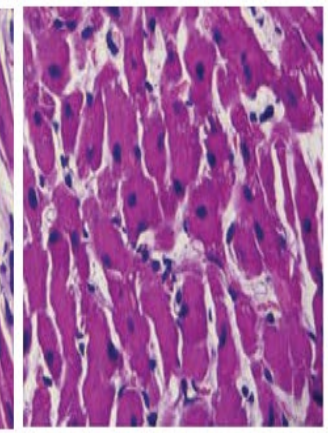

$\mathrm{C}$

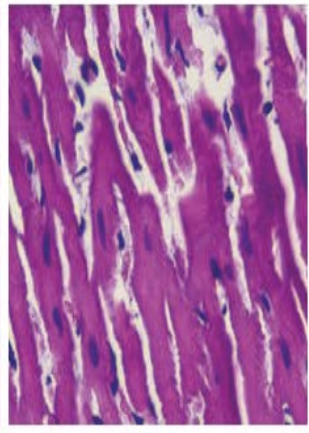

D

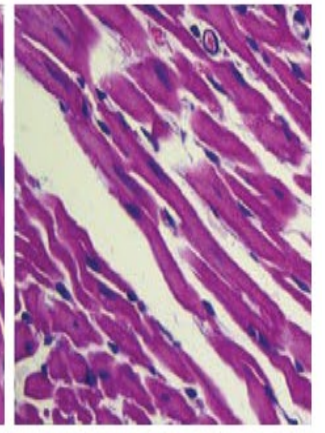

E

Fig. 1: Histopathological changes of rat heart after TA treatment (the representative microphotograph, 400x)

ratio was significantly decreased $(\mathrm{p}<0.05)$. Rat heart sections stained with H\&E were used for morphological analysis, as shown in fig. 1. A significant increase in the cross-sectional area of cardiomyocytes was observed in the AAB group, but this increase, decreased after TA treatment. Masson trichrome staining was used to detect the distribution of extracellular matrix and observe the morphological changes of collagen, the results indicating the development of fibrosis in heart tissue. Masson trichrome staining showed that the interstitial fibrosis increased in the AAB group and this increase was significantly decreased in the group treated with TA.

Fig. 2 shows that in the sham group, c-fos, c-jun, IL- $1 \beta$, and TNF- $\alpha$ were mainly associated with low levels of cell damage. After blood pressure overload, the positive staining of the above parameters was more comprehensive and stronger in the area around cardiomyocytes than that in the sham group (fig. $2 \mathrm{~A}$ and fig. $2 \mathrm{~B}, \mathrm{p}<0.01)$. In contrast, the expression of $\mathrm{c}$-jun and $\mathrm{c}-\mathrm{fos}$ in rat heart decreased significantly after the low or high doses of TA. The expression trend of IL-
$1 \beta$ and TNF- $\alpha$ was similar to that of c-jun and c-fos (fig. 2C and fig. 2D).

We detected the expression of TGF- $\beta$ and MMP-9 by the immunohistochemical method to explore the mechanism of TA against cardiac fibrosis. In the sham group, TGF- $\beta$ was expressed at a low level (fig. 3A). Compared with the sham group, the percentage area of TGF- $\beta$ immunostaining in the AAB group increased five times $(p<0.01)$. Compared with the AAB group, both low dose and high dose TA treatment significantly decreased the expression of TGF- $\beta(p<0.01)$. Fig. 3B shows that the expression of MMP-9 is opposite to that of TGF- $\beta$ in different groups.

Fig. 4 shows the levels of CK, CK-MB, and LDH in the sham group and the experimental group. In the AAB group, the above parameters increased significantly $(\mathrm{p}<0.01)$, CK and CK-MB increased by $53.72 \%$ and $78.83 \%$, respectively, compared with the sham group, the LDH decreased by $42.54 \%$. Compared with the $\mathrm{AAB}$ group, the value in the TA group decreased $(p<0.01)$. 
A

c-fos

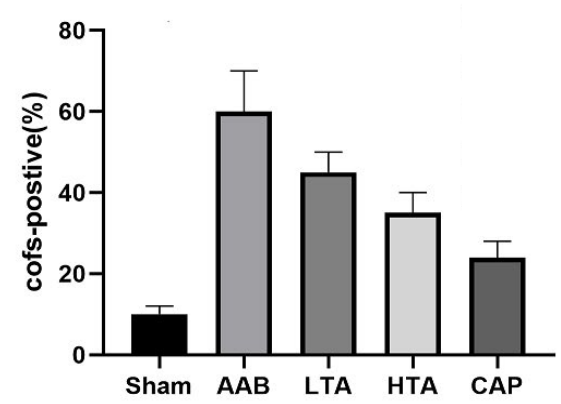

C

IL-1 $\beta$

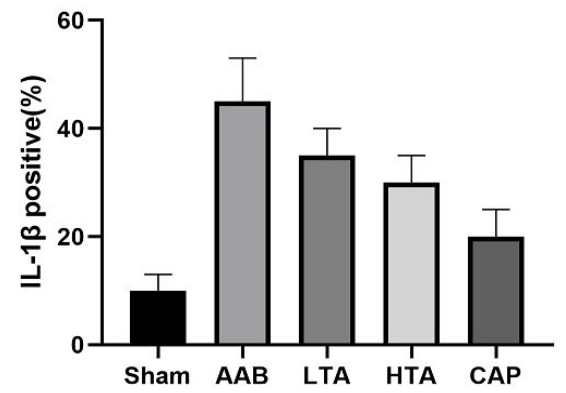

Fig. 2: Effect of TA on immunohistochemistry

TGF- $\beta$

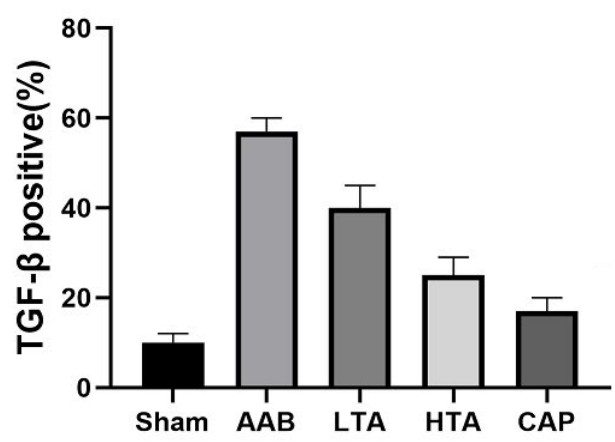

B

c-jun

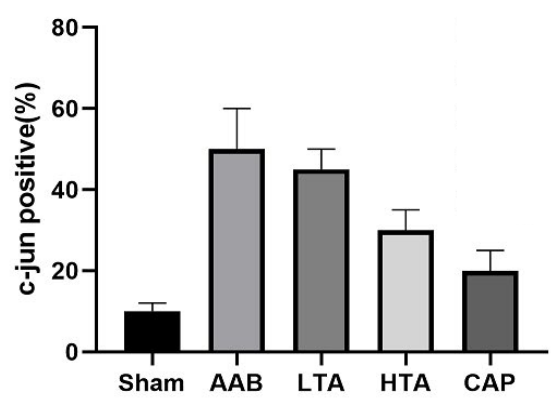

D

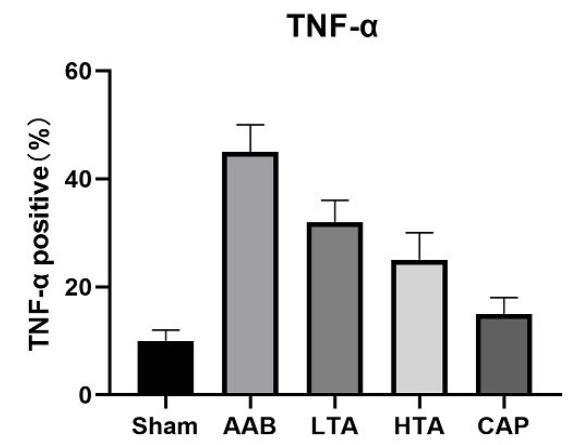

A

LDH

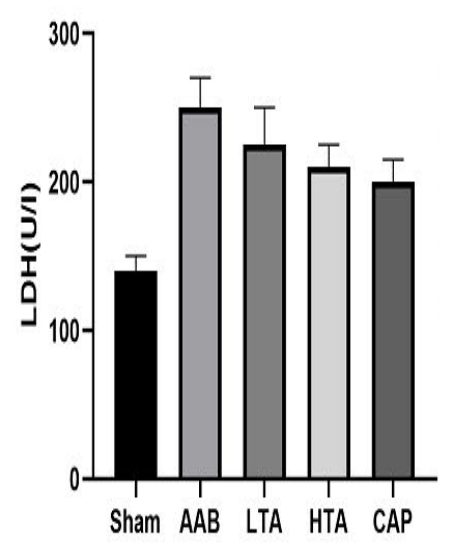

Fig. 3: Expression of TGF- $\beta$ and MMP-9
CK

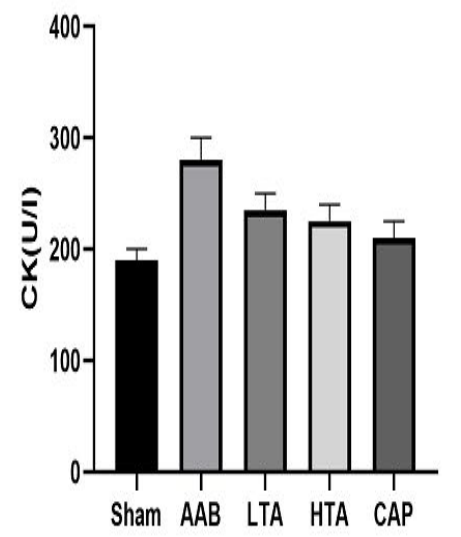

MMP-9

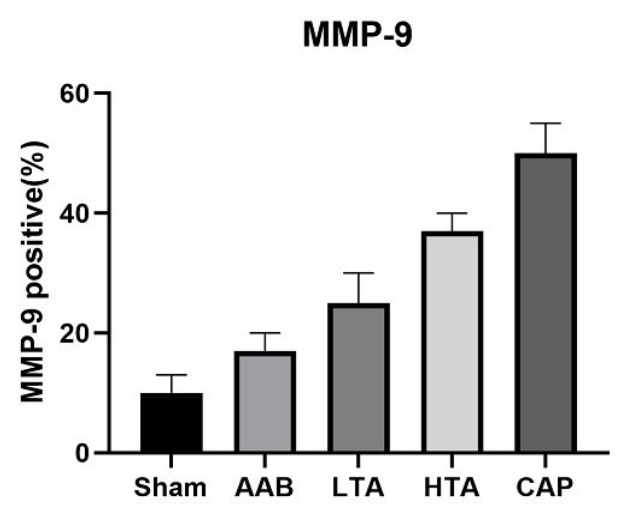

B

Fig. 4: Effect of TA on cardiac markers 
As shown in fig. 5, compared with the sham group, the content of MDA in the AAB group increased significantly $(110.02 \%)$, and the level of catalase decreased by $48.78 \%(\mathrm{p}<0.01)$. Compared with the sham group, the activity of superoxide dismutase in the AAB group decreased by $62.45 \%$ and $51.64 \%$. After pretreatment with TA $(20 \mathrm{mg} / \mathrm{kg}$ and $40 \mathrm{mg} / \mathrm{kg})$, these changes significantly returned to the normal level.

The results of western blot (fig. 6) showed that compared with the sham group, the expression of bax and caspase- 3 in the AAB group was up regulated, while the expression of bcl-2 was down regulated. These changes may increase apoptosis and lead to further deterioration of heart injury. TA $(20 \mathrm{mg} / \mathrm{kg}$ and $40 \mathrm{mg} / \mathrm{kg})$ treatment can inhibit almost all the side effects of AAB.

Fig. 7A shows that $4 \mathrm{w}$ after AAB modeling, TA treatment prevented the significant decrease of plasma NO level in the AAB group. Compared with the control

SOD

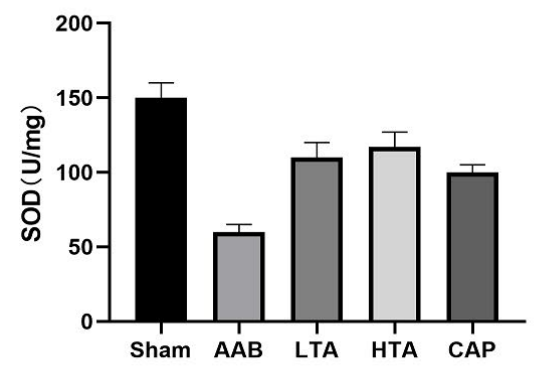

CAT

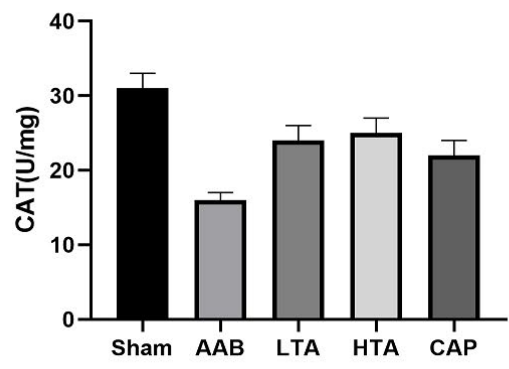

group, the expression level of nitric oxide synthase (NOS) protein in the AAB group was significantly lower than that of the sham group $(\mathrm{p}<0.01)$. A high dose of TA could increase the expression level of e-NOS protein significantly $(\mathrm{p}<0.01)($ fig. $7 \mathrm{C})$. Therefore, the increase of NO signaling system caused by TA therapy may be due to reverse pressure overload induced by cardiac remodeling.

After $8 \mathrm{w}$ of AAB modeling, the concentration of plasma endothelin-1 increased significantly $(\mathrm{p}<0.01$, fig. 7B). Therefore, after TA treatment, elevated endothelin-1 plasma levels decreased significantly at the 4th $\mathrm{W}$ (fig. 7B). By preventing endothelial cells in the signaling system, TA seems to counteract stress overload induced heart remodeling.

Compared with the sham group, AT1R, AT2R, and p-ERK $1 / 2$ increased significantly in the AAB group. Compared with the $\mathrm{AAB}$ group, low dose and high dose
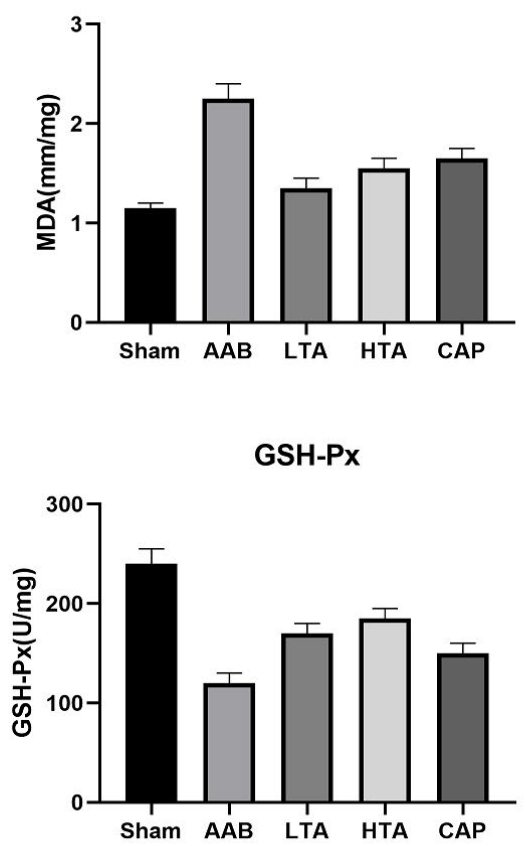

Fig. 5: Effect of TA on oxidative stress
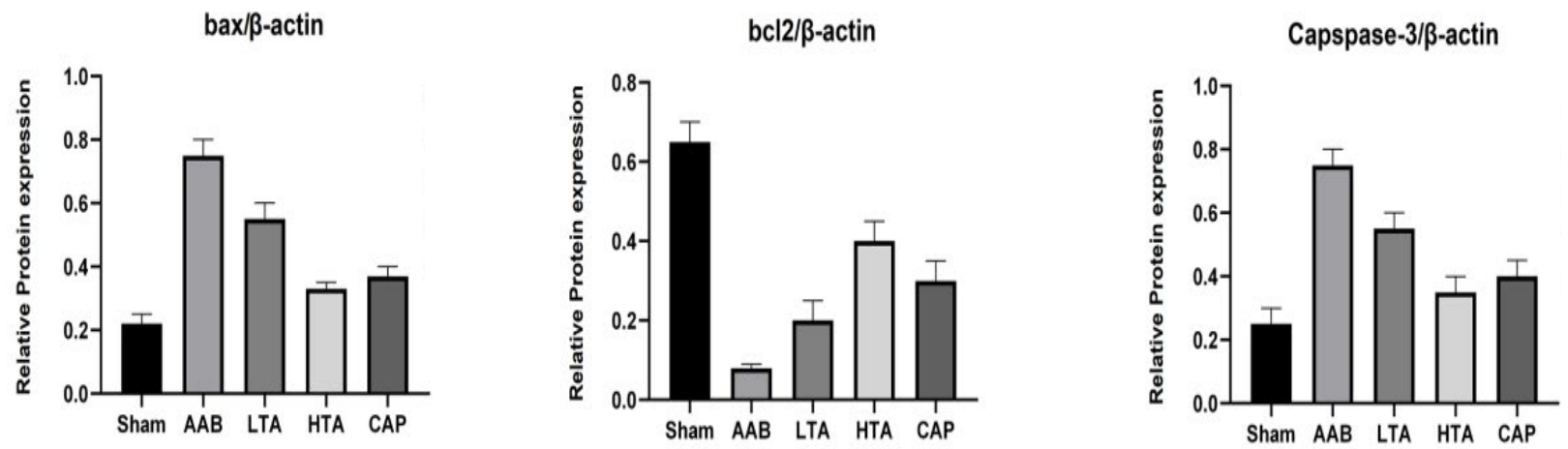

Fig. 6: Effect of TA on apoptosis factors 
TA treatment led to the decrease of AT1R, AT2R, and p-ERK1/2 $(\mathrm{p}<0.01)$ (fig. 8). This suggests that it may play a significant therapeutic role by interfering with the local renin-angiotensin system.

Cardiac hypertrophy induced by pressure overload was caused by an increase in the number of intracellular organelles (including mitochondria) resulting in an increase in the volume of cardiomyocytes. Mitochondria was the main source of energy for cells, and they convert nutrients into energy through cellular respiration. The flexibility of cardiac metabolism was very important. In the process of pressure overload induced cardiac hypertrophy, fatty acids were transferred to glucose as the main substrate of energy production. In the end stage heart failure, mitochondrial dysfunction may reduce the substrate oxidation rate, reduce the energy production and increase the formation of reactive oxygen species (ROS) ${ }^{[20]}$. Under high oxidative stress, cell dysfunction, necrosis and/or apoptosis were induced $^{[20,21]}$. In addition, abnormal myocardial blood flow can damage the myocardial oxygen transport and lead to maladaptation remodeling. It in turn induces the migration of macrophages, monocytes and neutrophils to the infarcted area of the left ventricle, which activates the intracellular signals and neurohormones and locates inflammation and fibrosis ${ }^{[22]}$. Therefore, cardiac hypertrophy induced by the pressure overload was a complex process involving cardiomyocyte growth and death, fibrosis, inflammation, oxidative stress and electrophysiological remodeling ${ }^{[23]}$. Our previous studies have shown that TA has antioxidant, antimutagenic, anti-inflammatory and anti-proliferation activities.

In this study, we studied the protective effect of TA on myocardial hypertrophy induced by pressure overload and its potential mechanism. Hemodynamic disturbance was one of the factors leading to myocardial hypertrophy and remodeling ${ }^{[24]}$. Epidemiological studies have reported that about $40 \%$ of myocardial infarction was associated with left ventricular systolic dysfunction, with decreased LVSP and $+\mathrm{dp} / \mathrm{dtmax}^{[25]}$. In our study, compared with the sham rats, the untreated animals developed cardiac dysfunction, LVSP and $+\mathrm{dp} /$ dtmax decreased within $8 \mathrm{w}$. TA significantly increased LVSP and $+d p / d t-m a x$. AAB impaired cardiac function, which was proved by the significant increase of LVEDP and the decrease of -dp/dtmax. In addition, the ratio of heart to body weight (HW/BW) was used to measure the degree of hypertrophy, which shows an increase of $20 \%-36 \%$. The myocardial morphology of all rats treated with TA was better than that of the $\mathrm{AAB}$ group. The results showed that the levels of CK, CK-MB, and $\mathrm{LDH}$ in the AAB group changed significantly, which was the early result of cell damage, loss of functional integrity and cell membrane permeability ${ }^{[26]}$. In this study, TA improved myocardial damage and myocardial hypertrophy.
A

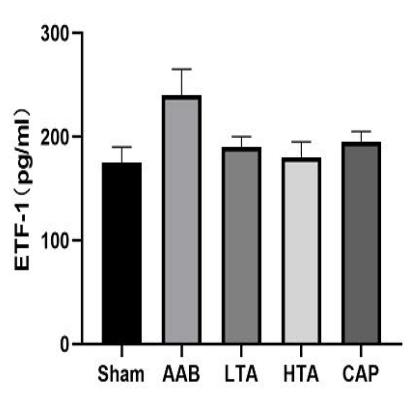

B

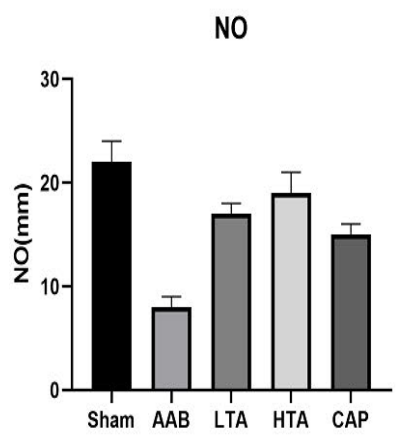

$\mathrm{C}$

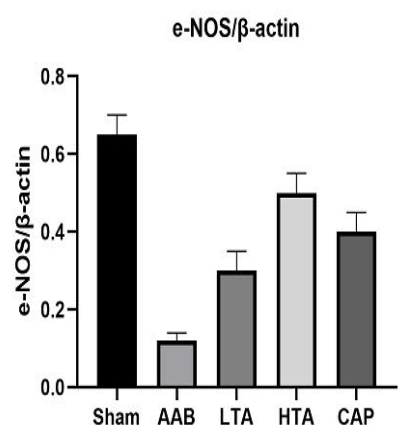

Fig. 7: Effect of TA on the expression of endothelin
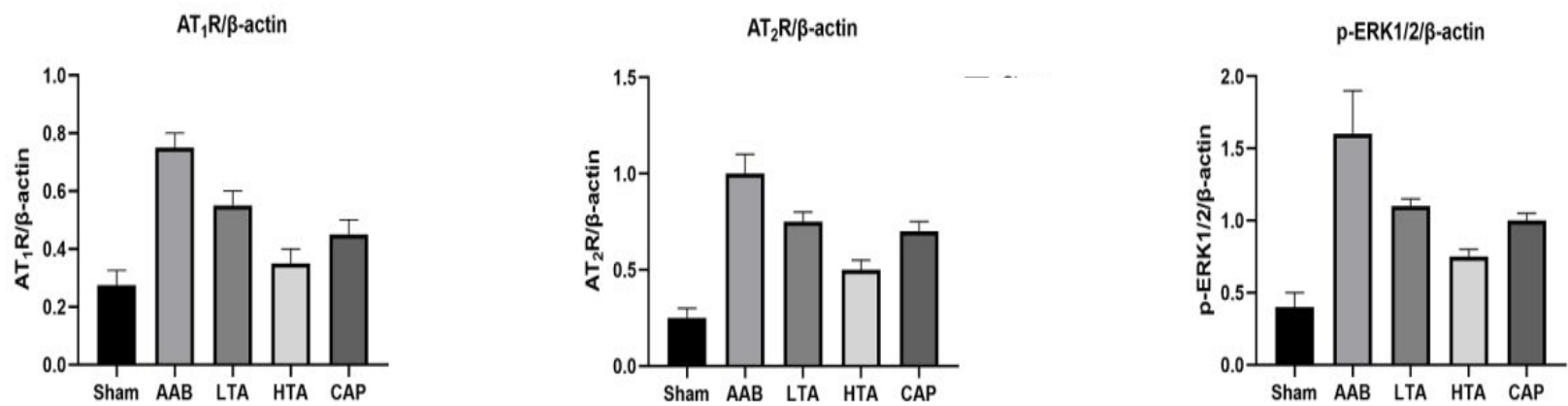

Fig. 8: Effect of TA on the expression of AT1R, AT2R, and p-ERK1/2 
Angiotensin II plays an important role in cardiac hypertrophy, fibrosis and apoptosis ${ }^{[27]}$. In addition, in the animal model of AAB, Angiotensin II also induced the expression of many immediately early genes (c-fos, c-jun) and late markers of cardiac hypertrophy, as well as growth factor genes TGF- $\beta$ and MMP$9^{[28,29]}$. TGF- $\beta$ was considered to be one of the major participants in the development of fibrosis and has been shown to reduce the expression and activity of MMPs, resulting in a decrease in extracellular matrix (ECM) (mainly collagen). Our results are also consistent with previous studies, that is, the low expression of c-fos, c-jun, and TGF- $\beta$ and the high expression of MMP-9. In the TA group, the area of cardiac fibrosis decreased gradually (fig. 1). AAB-mediated myocardial fibrosis was alleviated by TA in a dose-dependent manner. In addition, the decrease in cardiac coefficient after TA treatment also supported the efficacy of TA in the treatment of AAB-induced cardiac fibrosis (Table 1).

In some studies, tissue renin-angiotensin system (RAS) has beendescribedasanindependentriskfactorforcardiac hypertrophy and congestive heart failure. Angiotensin II plays an important role in cardiac hypertrophy. Two major subtypes of angiotensin II receptor (AT1 and AT2) have been identified in the mammals by subtype specific receptor blockers and cloning of their respective complementary Deoxyribonucleic acid (cDNAs ${ }^{[25,30]}$. The pathophysiological function and signal mechanism of AT2R was not clear, and there was almost no resemblance to $A T 1 R^{[31,32]}$. AT1R shows strong cell growth and proliferation activity, while AT2R usually inhibits the growth of various cultured cells. However, it was also reported that AT2R stimulation led to the growth promotion in vascular smooth muscle cells (VSMCs). In rat heart, angiotensin II-induced apoptosis was mediated by AT1R, not by AT2R. Study also found that $^{[32]}$ the mice with AT2R gene deletion lost the ability to develop cardiac hypertrophy in response to pressure overload or chronic angiotensin II infusion, while wild-type animals developed hypertrophy. At the same time, some studies have shown that pathological hypertrophy and failure of the human heart were related to the increased expression of AT1 and AT2 receptors $^{[33-35]}$. In this study, the expression of AT1R and AT2R in the AAB group was significantly higher than that in the sham group $(p<0.01)$. Compared with AAB group, the expression of AT1R and AT2R in the TA group decreased significantly $(p<0.01)$. Our results are consistent with the findings of Rekha Yesudas et al. that exposure to TA (at a concentration of
$12.5-100 \mu \mathrm{g} / \mathrm{ml}$ ) down-regulated the specific binding of AT1R within 2-24 h, and there was no change in affinity for angiotensin II receptor in vitro ${ }^{[17]}$.

Cardiac hypertrophy was widely involved in the MAPK signal pathway, including $\mathrm{p} 38$, c-Jun $\mathrm{N}$-terminal kinase (JNK), and extracellular signal-regulated kinase (ERK) [36]. The activation of ERK increasing the downstream expression of genes such as c-fos and c-jun, which played an important role in the cell cycle and regulate the activity of caspase- 3 and the expression of bax and bcl- $2^{[36,37]}$. These transcription factors, also known as immediately early genes, which can respond to many different cell damage stimuli ${ }^{[38]}$. In addition, endothelin-1 can accelerate the proliferation of smooth muscle cells by increasing the expression of c-fos and c-jun, which was an important part of activated protein- 1 . The activation of AT1R leads to the stimulation of transcription factors such as activator protein 1 (AP-1) and Nuclear factor $\kappa \mathrm{B}(\mathrm{NF}-\kappa \mathrm{B})^{[39]}$. TNF- $\alpha$ and IL- $1 \beta$ were activated by the ubiquitous NF- $\kappa$ B pathway. The binding of TNF- $\alpha$ and IL-1 $\beta$ receptor has been shown to induce the activation of NF- $\kappa B$. Based on these results, our study revealed that mitogen-activated protein kinase/ERK kinase (MEK)/ERK is a key regulator of cardiac hypertrophy and plays an important role in the antihypertensive effect of TA. We found that EKR1/2 showed a high level of phosphorylation under the pressure overload, which was reduced by the treatment with TA. We also observed that after treatment, the percentage of active IL- $1 \beta$, TNF- $\alpha$ and caspase- 3 in the myocardium was reduced, while the expression of bax and bcl-2 in signal transduction was increased.

Superoxide dismutase, catalase, glutathione peroxidase, and MDA were known as the free radical scavenging antioxidants, which were the first line of defense against oxidative damage. In our study, we observed that the decrease of the superoxide dismutase, catalase, glutathione peroxidase, and MDA activities in $\mathrm{AAB}$ rats was significantly improved in the treatment group. The increase of endogenous antioxidant activity was an indicator of structural integrity and myocardial protection, which was achieved by TA treatment. Because the endothelial dysfunction was significantly improved after the angiotensin converting enzyme was blocked by AT1R antagonist, we hypothesized that the angiotensin converting enzyme may lead to the improvement of endothelial dysfunction.

The endothelial dysfunction has been observed in a variety of CVDs, coronary artery disease, and heart failure. The pathophysiological mechanism of 
endothelial dysfunction was closely related to the decrease of NO bioavailability and the increase of endothelin-1 synthesis ${ }^{[40]}$. Blocking RAS with AT1R significantly improved the endothelial dysfunction ${ }^{[41]}$. In addition, it has been confirmed that the up regulation of NO was associated with the elevated blood pressure, and the up regulation of e-NOS helps to inhibit vascular tension and reduce pathological remodeling of blood vessels and heart ${ }^{[42]}$. The increase of NO and e-NOS content and the decrease of endothelin-1 level observed in TA group suggest that TA may provide a protective effect on vascular endothelium.

This study shows that TA treatment can improve AAB-induced myocardial hypertrophy effectively. Its cardioprotective effect is partly attributed to the reduction of myocardial oxidative stress, inhibition of inflammation, inhibition of fibrosis, reduction of apoptosis, increase of NO level, decrease of endothelin-1 level and down-regulation of AT1R.

\section{Author's contributions:}

Jianming Li conceived and designed the experiments; Lulu Wang, Xiaolong Li, Mim Yu and Yan Xuperformed the experiments; Xin Guo analyzed the data and wrote the paper.

\section{Acknowledgements:}

This work was supported by Affiliated Taikang Xianlin Drum Tower Hospital, Medical School of Nanjing University.

\section{Conflict of Interests:}

The authors declared no conflict of interest.

\section{REFERENCES}

1. Krstevska M, Dzhekova-Stojkova S, Bosilkova G. Menopause, coronary artery disease and antioxidants. Clin Chem Lab Med 2001;39(7):641-4.

2. Farre AL, Casado S. Heart failure, redox alterations, and endothelial dysfunction. Hypertension 2001;38(6):1400-5.

3. Morishita R, Higaki J, Miyazaki M, Ogihara T. Possible role of the vascular renin-angiotensin system in hypertension and vascular hypertrophy. Hypertension 1992;19(2):62.

4. Gao S, Long CL, Wang RH, Wang H. KATP activation prevents progression of cardiac hypertrophy to failure induced by pressure overload via protecting endothelial function. Cardiovasc Res 2009;83(3):444-56.

5. Rathore HA, Munavvar AS, Abdullah NA, Khan AH, Fathihah $\mathrm{B}$, NurJannah $\mathrm{MH}$, et al. Interaction between renin-angiotensin and sympathetic nervous systems in a rat model of pressure overload cardiac hypertrophy. Auton Autacoid Pharmacol 2009;29(4):171-80.

6. Rohini A, Agrawal N, Koyani CN, Singh R. Molecular targets and regulators of cardiac hypertrophy. Pharmacol Res
2010;61(4):269-80.

7. Weiss CS, Hagenmuller M, Pichler M, Munz S, Ochs M, Buss SJ, et al. Activation of PPAR $\gamma$ by pioglitazone does not attenuate left ventricular hypertrophy following aortic banding in rats. Naunyn Schmiedebergs Arch Pharmacol 2010;381(4):285-95.

8. Renaud SD, de Lorgeril M. Wine, alcohol, platelets, and the French paradox for coronary heart disease. Lancet 1992;339:1523-6.

9. Criqui MH, Ringel BL. Does diet or alcohol explain the French paradox? Lancet 1994;344:1719-23.

10. Cohen SD, Khairallah EA. Selective protein arylation and acetaminophen-induced hepatotoxicity. Drug Metab Rev 1997;29:59-77.

11. King AM, Young G. Characteristics and occurrence of phenolic phytochemicals. J Am Diet Assoc 1999;99(2):213-8.

12. Guerrero RF, Garcia-Parrilla MC, Puertas B, Cantos-Villar E. Wine, resveratrol and health: a review. Nat Prod Commun 2009;4(5):635-58.

13. Andrade Jr RG, Dalvi LT, Silva Jr JM, Lopes GK, Alonso A, Hermes-Lima M. The antioxidant effect of tannic acid on the in vitro copper-mediated formation of free radicals. Arch Biochem Biophys 2005;437(1):1-9.

14. Wu LT, Chu CC, Chung JG, Chen CH, Hsu LS, Liu JK, et al. Effects of tannic acid and its related compounds on food mutagens or hydrogen peroxide-induced DNA strands breaks in human lymphocytes. Mutat Res 2004;556:75-82.

15. Chen SC, Chung KT. Mutagenicity and antimutagenicity studies of tannic acid and its related compounds. Food Chem Toxicol 2000;38(1):1-5.

16. Erdelyi K, Kiss A, Bakondi E, Bai P, Szabo C, Gergely P, et al. Gallotannin inhibits the expression of chemokines and inflammatory cytokines in A549 cells. Mol Pharmacol 2005;68(3):895-904.

17. Yesudas R, Gumaste U, Snyder R, Thekkumkara T. Tannic acid down-regulates the angiotensin type 1 receptor through a MAPK-dependent mechanism. Mol Endocrinol 2012;26(3):458-70.

18. Schunkert H, Weinberg EO, Bruckschlegel G, Riegger AJ, Lorell BH. Alteration of growth responses in established cardiac pressure overload hypertrophy in rats with aortic banding. J Clin Invest 1995;96(6):2768-74.

19. Hong Y, Hui SC, Chan TY, Hou JY. Effect of berberine on regression of pressure-overload induced cardiac hypertrophy in rats. Am J Chin Med 2002;30(4):589-99.

20. Seddon M, Looi YH, Shah AM. Oxidative stress and redox signalling in cardiac hypertrophy and heart failure. Heart 2007;93(8):903-7.

21. Takimoto E, Kass DA. Role of oxidative stress in cardiac hypertrophy and remodeling. Hypertension 2007;49(2):241-8.

22. Ingwall JS. Energy metabolism in heart failure and remodelling. Cardiovasc Res 2009;81(3):412-9.

23. Burchfield JS, Xie M, Hill JA. Pathological ventricular remodeling: mechanisms: part 1 of 2 . Circulation 2013;128(4):388-400.

24. Katz AM. Heart failure: a hemodynamic disorder complicated by maladaptive proliferative responses. J Cell Mol Med 2003;7(1):1-10.

25. Albert NM, Lewis C. Recognizing and managing asymptomatic left ventricular dysfunction: after myocardial infarction. Crit Care Nurse 2008;28(2):20-37.

26. Farvin KS, Anandan R, Kumar SH, Shiny KS, Sankar TV, Thankappan TK. Effect of squalene on tissue defense system in 
isoproterenol-induced myocardial infarction in rats. Pharmacol Res 2004;50(3):231-6.

27. Higashi M, Shimokawa H, Hattori T, Hiroki J, Mukai Y, Morikawa $\mathrm{K}$, et al. Long-term inhibition of Rho-kinase suppresses angiotensin II-induced cardiovascular hypertrophy in rats in vivo: effect on endothelial NAD (P) H oxidase system. Circ Res 2003;93(8):767-75.

28. Wang YX, da Cunha V, Martin-McNulty B, Vincelette J, Li W, Choy DF, et al. Inhibition of Rho-kinase by fasudil attenuated angiotensin II-induced cardiac hypertrophy in apolipoprotein E deficient mice. Eur J Pharmacol 2005;512:215-22.

29. Lee SD, Chu CH, Huang EJ, Lu MC, Liu JY, Liu CJ, et al. Roles of insulin-like growth factor II in cardiomyoblast apoptosis and in hypertensive rat heart with abdominal aorta ligation. Am J Physiol Endocrinol Metab 2006;291(2):E30614.

30. Lijnen P, Petrov V. Antagonism of the renin-angiotensin system, hypertrophy and gene expression in cardiac myocytes. Methods Find Exp Clin Pharmacol 1999;21(5):363-74.

31. Takai S, Yamamoto D, Jin D, Inagaki S, Yoshikawa K, Tanaka $\mathrm{K}$, et al. Inhibition of matrix metalloproteinase-9 activity by lisinopril after myocardial infarction in hamsters. Eur $\mathrm{J}$ Pharmacol 2007;568:231-3.

32. Usunier B, Benderitter M, Tamarat R, Chapel A. Management of fibrosis: the mesenchymal stromal cells breakthrough. Stem Cells Int 2014:1-26.

33. Kambayashi Y, Bardhan S, Takahashi K, Tsuzuki S, Inui H, Hamakubo T, et al. Molecular cloning of a novel angiotensin II receptor isoform involved in phosphotyrosine phosphatase inhibition. J Biol Chem 1993;268:24543-6.

34. Mukoyama M, Nakajima M, Horiuchi M, Sasamura H, Pratt RE, Dzau VJ. Expression cloning of type 2 angiotensin II receptor reveals a unique class of seven-transmembrane receptors. J Biol Chem 1993;268:24539-42.

35. Matsubara H. Pathophysiological role of angiotensin II type
2 receptor in cardiovascular and renal diseases. Circ Res 1998;83(12):1182-91.

36. De Gasparo M, Catt KJ, Inagami T, Wright JW, Unger TH. International union of pharmacology. XXIII. The angiotensin II receptors. Pharmacol Rev 2000;52(3):415-72.

37. Diep QN, El Mabrouk M, Yue P, Schiffrin EL. Effect of AT1 receptor blockade on cardiac apoptosis in angiotensin II-induced hypertension. Am J Physiol Heart Circ Physiol 2002;282(5):1635-41.

38. Oldenhof AD, Shynlova OP, Liu M, Langille BL, Lye SJ. Mitogen-activated protein kinases mediate stretch-induced c-fos mRNA expression in myometrial smooth muscle cells. Am J Physiol Cell Physiol 2002;283(5):1530-9.

39. Shaulian E, Karin M. AP-1 in cell proliferation and survival. Oncogene 2001;20(19):2390-400.

40. Sawyer DB, Siwik DA, Xiao L, Pimentel DR, Singh K, Colucci WS. Role of oxidative stress in myocardial hypertrophy and failure. J Mol Cell Cardiol 2002;34(4):379-88.

41. Deschamps AM, Spinale FG. Pathways of matrix metalloproteinase induction in heart failure: bioactive molecules and transcriptional regulation. Cardiovasc Res 2006;69(3):666-76.

42. O’Dea E, Hoffmann A. NF-kappaB signaling. Wiley Interdiscip Rev Syst Biol Med 2009;1:107-15.

This is an open access article distributed under the terms of the Creative Commons Attribution-NonCommercial-ShareAlike 3.0 License, which allows others to remix, tweak, and build upon the work non-commercially, as long as the author is credited and the new creations are licensed under the identical terms

This article was originally published in a special issue, "Trends in Therapeutic Management of Various Clinical Conditions II" Indian J Pharm Sci 2021:83(2)Spl issue;88-97 